\title{
Reactive Oxygen Species Function to Mediate the Fe Deficiency Response in an Fe-Efficient Apple Genotype: An Early Response Mechanism for Enhancing Reactive Oxygen Production
}

\section{OPEN ACCESS}

Edited by: Irene Murgia

University of Milan, Italy

Reviewed by: Hannetz Roschzttardtz, Pontifical Catholic University of Chile,

Ferenc Fodor,

Eötvös Loránd University, Hungary

${ }^{*}$ Correspondence:

Yi Wang

wangyi@cau.edu.cn

Zhenhai Han

rschan@cau.edu.cn

tThese authors have contributed equally to this work

Specialty section: This article was submitted to Plant Physiology, a section of the journal

Frontiers in Plant Science

Received: 12 August 2016 Accepted: 02 November 2016 Published: 16 November 2016

Citation:

Sun $C$, Wu T, Zhai L, Li D, Zhang $X$, $X u X, M a H$, Wang $Y$ and Han $Z$ (2016) Reactive Oxygen Species Function to Mediate the Fe Deficiency

Response in an Fe-Efficient Apple

Genotype: An Early Response Mechanism for Enhancing Reactive

Oxygen Production.

Front. Plant Sci. 7:1726. doi: 10.3389/fpls.2016.01726

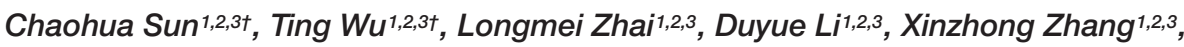
Xuefeng $\mathrm{Xu}^{1,2,3}$, Huiqin Ma1,2, Yi Wang ${ }^{1,2,3 *}$ and Zhenhai Han ${ }^{1,2,3 *}$
\end{abstract}

${ }^{1}$ Institute for Horticultural Plants, College of Horticulture, China Agricultural University, Beijing, China, ${ }^{2}$ Key Laboratory of Physiology and Molecular Biology of Tree Fruit of Beijing, China Agricultural University, Beijing, China, ${ }^{3}$ Beijing Collaborative Innovation Center for Eco-environmental Improvement with Forestry and Fruit Trees, China Agricultural University, Beijing, China

Reactive oxygen species (ROS) are important signaling molecules in plants that contribute to stress acclimation. This study demonstrated that ROS play a critical role in Fe deficiency-induced signaling at an early stage in Malus xiaojinensis. Once ROS production has been initiated, prolonged Fe starvation leads to activation of ROS scavenging mechanisms. Further, we demonstrated that ROS scavengers are involved in maintaining the cellular redox homeostasis during prolonged Fe deficiency treatment. Taken together, our results describe a feedback repression loop for ROS to preserve redox homeostasis and maintain a continuous Fe deficiency response in the Fe-efficient woody plant $M$. xiaojinensis. More broadly, this study reveals a new mechanism in which ROS mediate both positive and negative regulation of plant responses to Fe deficiency stress.

Keywords: ROS, Fe deficiency, early response, Malus xiaojinensis, woody plant

\section{INTRODUCTION}

Fe is an essential micronutrient required for a wide variety of cellular functions in plant growth and development. Although Fe is abundant in the soil, Fe availability is limited due to its poor solubility in an oxygen-rich atmosphere (Briat et al., 1995; Crichton and Pierre, 2001; Darbani et al., 2013). Plants have evolved two distinct strategies of Fe uptake to cope with Fe deficiency (Marschner et al., 1986; Römheld and Marschner, 1990; Briat et al., 1995). Non-graminaceous plants use a reduction strategy that involves the reduction of ferric chelates at the root surface and the absorption of the ferrous $\mathrm{Fe}$ across the root plasma membrane (Strategy I), whereas graminaceous plants secrete phytosiderophores to enhance Fe uptake from the soil (Strategy II) (Marschner, 2011). In plants employing Strategy I, the regulation of root Fe (III) reductase and proton extrusion activity are thought to be crucial events controlling Fe acquisition, and the roles of auxin, NO, and ethylene in the regulation of Fe deficiency responses are widely accepted (Schmidt and Bartels, 1996; Romera and Alcántara, 2004; Chen et al., 2010; Wu et al., 2012).

The main reactive oxygen species (ROS) include non-radical molecules such as singlet oxygen $\left({ }^{1} \mathrm{O}_{2}\right)$ and hydrogen peroxide $\left(\mathrm{H}_{2} \mathrm{O}_{2}\right)$, as well as free radicals such as superoxide $\left(\mathrm{O}_{2}{ }^{-}\right)$and 
hydroxyl radicals $(\bullet \mathrm{OH})$ (da Silva et al., 2008). Besides their harmful effects, ROS act as signaling molecules that regulate plant development, and biotic and abiotic stress responses (Mittler et al., 2004). Recent research has focused on ROS metabolism (Krasensky and Jonak, 2012; Noctor et al., 2014), and sensory and signaling networks (Dietz, 2008; Miller et al., 2010; Krasensky and Jonak, 2012; Baxter et al., 2014), as well as the cross-talk with other signaling pathways (Suzuki et al., 2012; Noctor et al., 2014).

As $\mathrm{Fe}$ is one constituent of the electron transport chain in mitochondria and chloroplasts, Fe deficiency can result in an imbalance of cellular redox. The role of ROS in Fe response regulation has not been well-defined, and they may play multiple roles. Glutathione (GSH) and ascorbate (ASC) act as ROS scavengers, which protect Arabidopsis seedlings from Fe deficiency, preserving cellular redox homeostasis and improving internal Fe availability (Ramírez et al., 2013). In addition, GSH and ASC levels were increased in cucumber and sugar beet exposed to conditions of Fe deficiency (Zaharieva et al., 1999; Zaharieva and Abadì, 2003). $\mathrm{H}_{2} \mathrm{O}_{2}$ is involved in the regulation of ferritins in response to excess $\mathrm{Fe}$ to alleviate oxidative stress in leaves (Ravet et al., 2009; Briat et al., 2010), flowers (Sudre et al., 2013), and roots (Ravet et al., 2012; Reyt et al., 2015). ROS production has also been demonstrated under Fe deficiency in sunflower and maize (Ranieri et al., 2001; Sun et al., 2007). ROS could also be linked with Fe deficiency regulation since they have been found associated with $\mathrm{NO}$ and ethylene in abiotic stress signaling (Brumbarova et al., 2015; Xia et al., 2015). Recently, an abiotic stress-induced transcription factor, ZAT12, was identified, which functions as a negative regulator of $\mathrm{Fe}$ acquisition, and the authors suggested $\mathrm{H}_{2} \mathrm{O}_{2}$ mediates the negative regulation of plant responses to prolonged stress (Le et al., 2016). Thus, the role of ROS in the regulation of Fe deficiency responses needs to be investigated further.

Some species, such as tomato (Solanum lycopersicum), lettuce (Lactuca sativa), peanut (Arachis hypogaea), and apple rootstock (Malus xiaojinensis and Malus baccata), show different levels of resistance to Fe deficiency among genotypes (Han et al., 1994, 1998; Wang and Li, 1995; Xu et al., 2009; Sun et al., 2013; Xia et al., 2014). Self-incompatible species, such as apple, have higher levels of genetic variation, and the use of highly heterozygous Malus genotypes allowed us to identify an Feefficient woody plant in which to study the role of ROS in the response to Fe deficiency. We proposed a model that Fe deficiency might trigger ROS production, which would then act as an early response signal to mediate and maintain an Fe deficiency-induced response.

\section{RESULTS}

\section{Fe Deficiency Induces ROS Production at an Early Stage and then Activates ROS Scavenging Mechanisms in M. xiaojinensis}

Both M. xiaojinensis and M. baccata are valued in China as native apple rootstocks. $M$. xiaojinensis performs Fe uptake with high efficiency (Han et al., 1994, 1998, 2005). However, compared with that in M. xiaojinensis, the Fe uptake efficiency in M. baccata is much lower. As shown in Figure 1, typical Fe deficiency symptoms resulting from low Fe treatment for 9 days were quite obvious in M. baccata but not in M. xiaojinensis (Figure 1A). $M$. xiaojinensis had higher active Fe content in roots than did $M$. baccata, indicating a variation in Fe uptake ability between the two Malus genotypes (Figure 1B). Further, our microtomography analysis of $\mathrm{Fe}$ distribution in roots of the two species confirmed this difference. The X-ray fluorescence (XRF) maps of the Fe distribution pattern in the roots showed the $\mathrm{Fe}$ content in $M$. xiaojinensis roots was higher than that in $M$. baccata roots (Figure 1C).

The ROS production in roots determined by DCFH-DA fluorescence was intensified at an early stage of Fe deficiency and then weakened after prolonged Fe deficiency (Figure 2D). $\mathrm{H}_{2} \mathrm{O}_{2}$ localization in the root was monitored by reaction of $\mathrm{CeCl}_{3}$. A clear signal was observed in the apoplast, particularly in the root of $M$. baccata at the prolonged Fe deficiency stage (Figure 2E).

The hypothesis that Fe deficiency can trigger ROS production was then tested. Total ROS and $\mathrm{H}_{2} \mathrm{O}_{2}$ were quantified in roots of $M$. xiaojinensis and $M$. baccata exposed to Fe deficiency. As shown in Figures 2A,B and Supplementary Figure S1, Fe deficiency was capable of triggering ROS and $\mathrm{H}_{2} \mathrm{O}_{2}$ production at the early Fe-deficient stage $(9 \mathrm{~h})$ in $M$. xiaojinensis, but not in $M$. baccata. Interestingly, after prolonged exposure to Fe deficiency, the ROS and $\mathrm{H}_{2} \mathrm{O}_{2}$ content was reduced in $M$. xiaojinensis after 1-3 days and was not significantly different from that in the Fe-sufficient treatment. This result was not observed in M. baccata. Catalase (CAT), surperoxide dismutase (SOD), and peroxidase (POD) can act as ROS scavengers, keeping cellular redox homeostasis under control. Total CAT, POD, and SOD levels quantified in roots exposed to Fe deficiency were increased at $9 \mathrm{~h}$ in $M$. xiaojinensis but were not affected in roots of $M$. baccata (Figure 3). These results suggest Fe deficiency can trigger ROS scavengers in order to maintain the cellular redox homeostasis in the early stage of Fe deficiency.

These results demonstrate that Fe deficiency is indeed capable of causing a significant accumulation of ROS in roots; however, the Fe-efficient species M. xiaojinensis could activate scavenging mechanisms to preserve the redox homeostasis during prolonged Fe deficiency treatment.

\section{Up-Regulation of the Fe Deficiency-Induced Response is Associated with Systemic ROS Production at an Early Stage}

As shown in Figure 2, Fe deficiency induced a significant increase in root ROS contents. Consistent with ROS production, the results showed that Fe deprivation caused a significant increase in root $\mathrm{Fe}$ (III) reductase activity of $M$. xiaojinensis at $9 \mathrm{~h}$ (Figure 2C). An attempt was therefore made to assess whether the Fe deficiency-induced alterations in root Fe (III) reductase activity and proton extrusion were mediated by ROS signaling. It was found that the Fe deficiency-induced increase in root ROS 


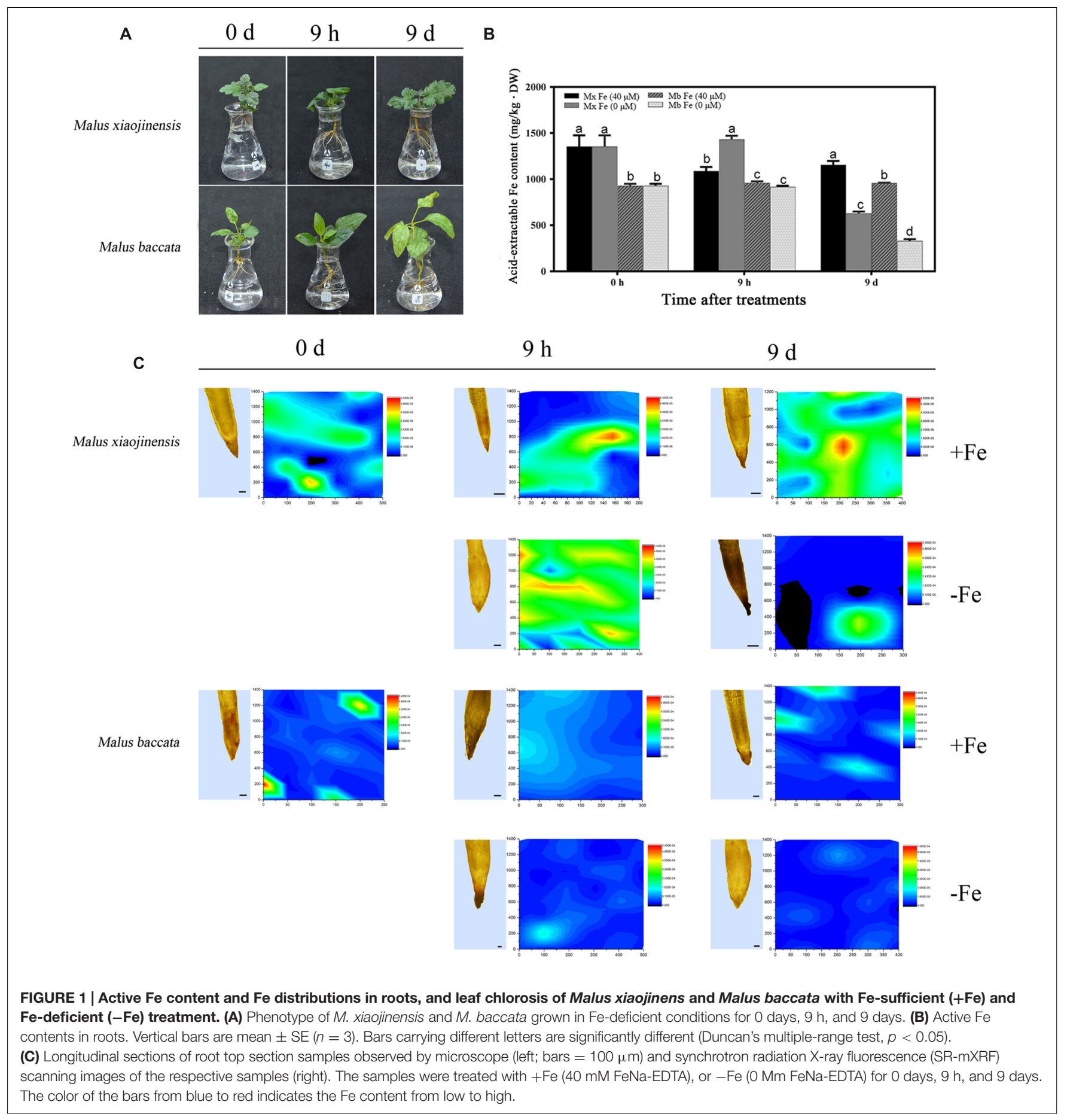

levels was correlated with the increased expression of MxFIT and MxBTSa (Figures 4A,D). The Arabidopsis ortholog of the FER gene, FIT, was identified from the 161 predicted bHLH proteins by microarray analysis (Bauer et al., 2007). FIT also plays an important role in positively regulating various iron deficiency inducible genes, including IRT1 and FRO2 (Yuan et al., 2005; Bauer et al., 2007). BRUTUS (BTS), a putative E3 ligase protein, with metal ion binding and DNA binding domains, which negatively regulates the response to iron deficiency (Long et al., 2010).

Next, it was determined whether ROS inhibitors blocked the Fe deficiency responses. The responses to Fe deficiency were markedly repressed by exposure to diphenyleneiodonium (DPI), which can block ROS production (Figures 5A-C). DPI application strongly inhibited the Fe deficiency-induced increase in reductase activity (Figures $5 \mathrm{~B}, \mathrm{E}$ ) and proton extrusion 

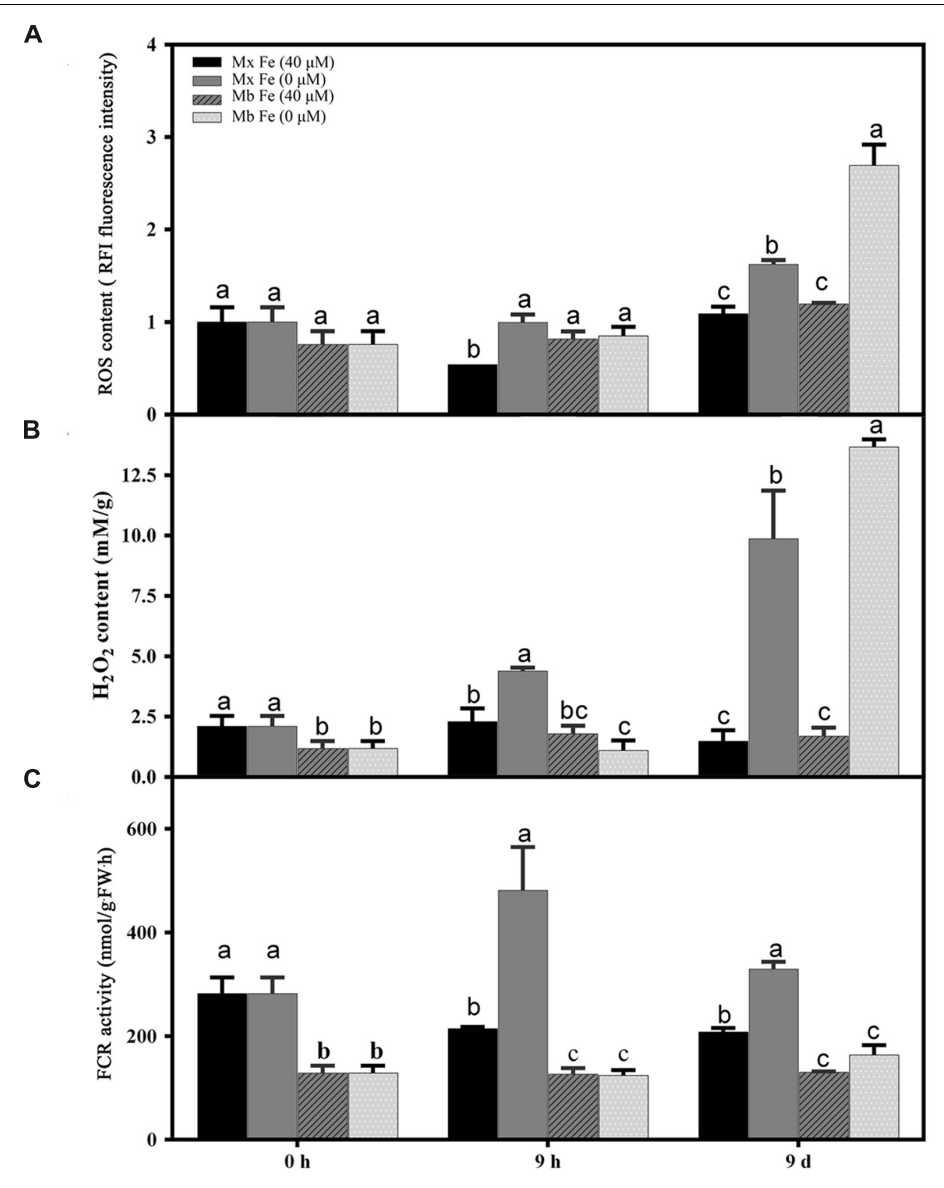

Time after treatments
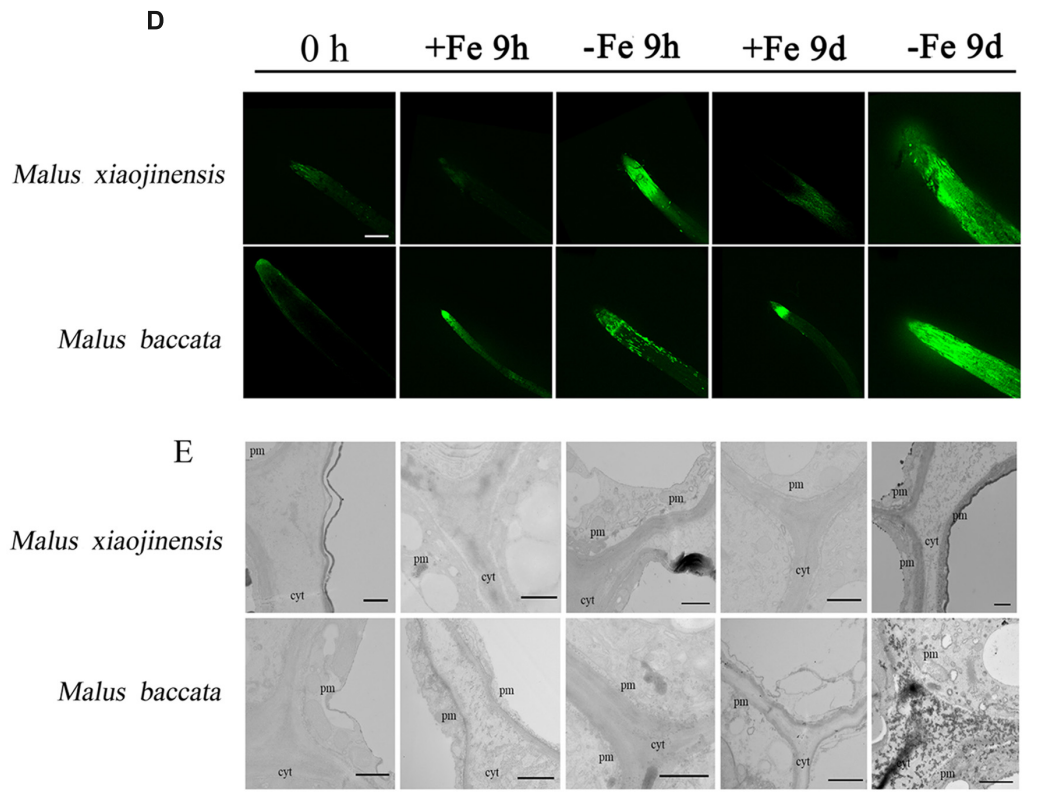

FIGURE 2 | Reactive oxygen species (ROS), $\mathrm{H}_{2} \mathrm{O}_{2}$ content, ferric-chelate reductase (FCR) activity, and tissue localization in the roots of

M. xiaojinensis (Mx) and $\mathbf{M}$. baccata $(\mathbf{M b})$ plants with Fe-sufficient (+Fe) and Fe-deficient (-Fe) treatment. (A) ROS content in root tips (3-5 mm).

(B) $\mathrm{H}_{2} \mathrm{O}_{2}$ content in roots. (C) FCR activity in roots. Values represent the mean and standard error of three replications. The dashed line is the critical value. (D) $\mathrm{ROS}$ system localization shown as green fluorescence from DCFH-DA in roots, bar $=500 \mu \mathrm{m}$. (E) Cytochemical localization of root tip; cyt, cytoderm; cm,

cytomembrane. Bar $=1 \mu \mathrm{m}$. Vertical bars are mean $\pm \mathrm{SE}(n=3)$. Bars carrying different letters are significantly different (Duncan's multiple-range test, $p<0.05)$. 
A

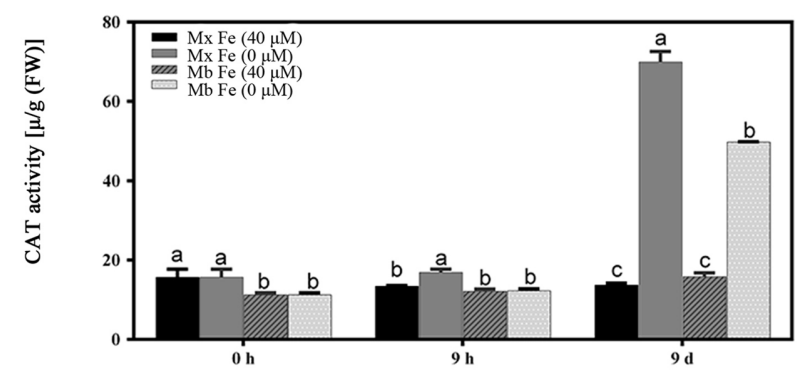

B

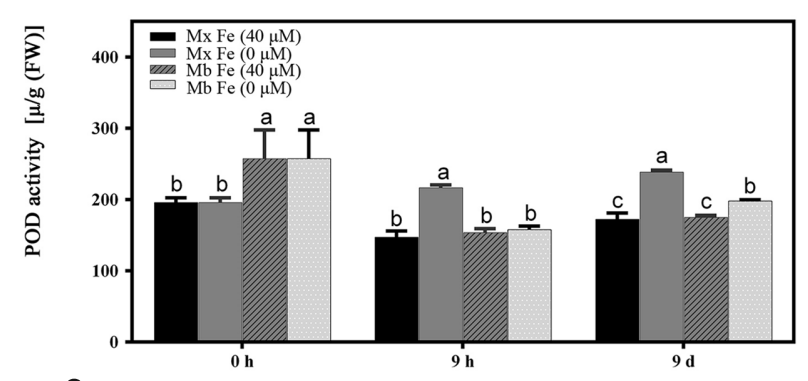

C

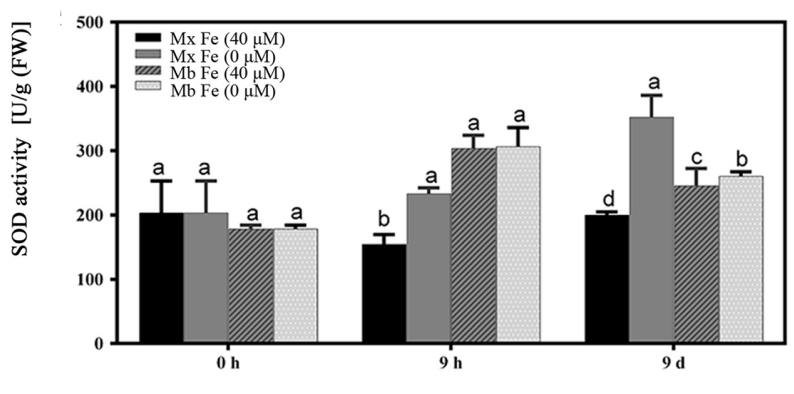

Time after treatments

FIGURE 3 | Oxidative stress-related enzyme activities in root tissues. (A) CAT enzyme activity of root tissues. (B) POD enzyme activity of root tissues. (C) SOD enzyme activity of root tissues. The values represent the mean and standard error of three replications. Vertical bars are mean $\pm \mathrm{SE}$ $(n=3)$. Bars carrying different letters are significantly different (Duncan's multiple-range test, $p<0.05$ ).

(Figure 5C). These results imply that a certain endogenous ROS level is necessary for the Fe deficiency-based induction of expression of transcription factors, such as FIT (Figure 5F). Taken together, these results demonstrate that ROS play a critical role in Fe deficiency-induced signaling at an early stage.

\section{M. xiaojinensis could Activate ROS Scavenging Mechanisms to Maintain a Persistent Fe Deficiency-Induced Response with Prolonged Fe Deficiency Treatment}

As described above, M. xiaojinensis and M. baccata are related plants but with a rather different ROS accumulation following prolonged Fe deficiency treatment. After 1 day of Fe deficiency, while the ROS content was decreased in M. xiaojinensis compared with the ROS content at 9 days (Supplementary Figure S1), both root $\mathrm{Fe}$ (III) reductase activity (Figure 6B) and proton extrusion (Figure 6C) were maintained at a higher level. Total CAT, POD, and SOD levels quantified in roots exposed to Fe deficiency were increased at day 9 in M. xiaojinensis and they were higher than those in roots of $M$. baccata during Fe deficiency (Figures 3A-C). These results suggest ROS scavengers are involved in maintaining the cellular redox homeostasis during prolonged Fe deficiency treatment.

Since $\mathrm{H}_{2} \mathrm{O}_{2}$ mediates the negative regulation of plant responses to prolonged $\mathrm{Fe}$ deficiency stress, $\mathrm{H}_{2} \mathrm{O}_{2}$ application experiments were performed in order to reveal the roles of ROS in the response of $M$. xiaojinensis to prolonged Fe deficiency stress. As shown in Figure 6, $\mathrm{H}_{2} \mathrm{O}_{2}$ application strongly inhibited the Fe deficiency-induced increase in reductase activity and proton extrusion at day 9. It was next determined whether the negative regulator $M x Z A T 12 c$ responded to $\mathrm{H}_{2} \mathrm{O}_{2}$ during prolonged Fe deficiency treatment; MxZAT12c was induced as expected (Figure 6H). Furthermore, $\mathrm{H}_{2} \mathrm{O}_{2}$ treatment prevented the response of MxFIT, MxIRT1, and MxBSTa to Fe deficiency (Figures 6F,G,I). From the expression pattern of these genes under $\mathrm{H}_{2} \mathrm{O}_{2}$ treatment, we deduced that ROS may act as a repressor signal of the Fe deficiency response upon prolonged Fe deficiency at day 9 .

\section{DISCUSSION}

We hypothesize that Fe deficiency might trigger ROS production in the Fe-efficient woody plant M. xiaojinensis, which would then act as an early response signal to mediate and maintain an $\mathrm{Fe}$ deficiency-induced response. Some studies support the involvement of $\mathrm{H}_{2} \mathrm{O}_{2}$ in the regulation of ferritins in response to excess Fe to prevent oxidative stress (Ravet et al., 2009, 2012; Briat et al., 2010; Sudre et al., 2013; Reyt et al., 2015), but how ROS participate in that regulation of Fe deficiency stress in woody plants remained unknown. Previous research has proposed that $\mathrm{H}_{2} \mathrm{O}_{2}$ can be considered an intermediate in the auto-regulatory suppression of FIT after prolonged Fe deficiency in Arabidopsis thaliana (Le et al., 2016). In the present study, Fe deficiency responses were markedly repressed by exposure to a ROS inhibitor at an early stage, which suggests that $\mathrm{H}_{2} \mathrm{O}_{2}$ is an enhancer of the early Fe deficiency response in M. xiaojinensis (Figure 5).

Compared with $A$. thaliana, a relatively high level of variation has been maintained between, or among, domesticated crops and their close wild relatives (Huang and Han, 2014). Selfincompatible species, such as apple, have higher levels of variation, and the use of highly heterozygous Malus genotypes allowed us to demonstrate that ROS could be an early stage signal to enhance the efficiency of $\mathrm{Fe}$ uptake in $\mathrm{Fe}$-efficient woody plants. By taking advantage of the distinct capabilities of two related woody species (M. xiaojinensis and M. baccata) to cope with Fe deficiency, we showed that ROS could be the hub for both positive and negative regulators dependent on an auto-regulatory loop requiring the ROS itself.

Our results showed that ROS content increased at an early stage of Fe deficiency treatment, then decreased with prolonged 


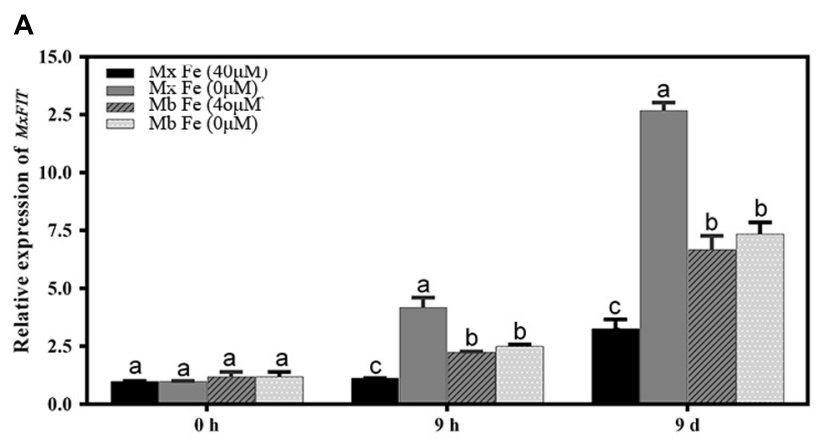

C

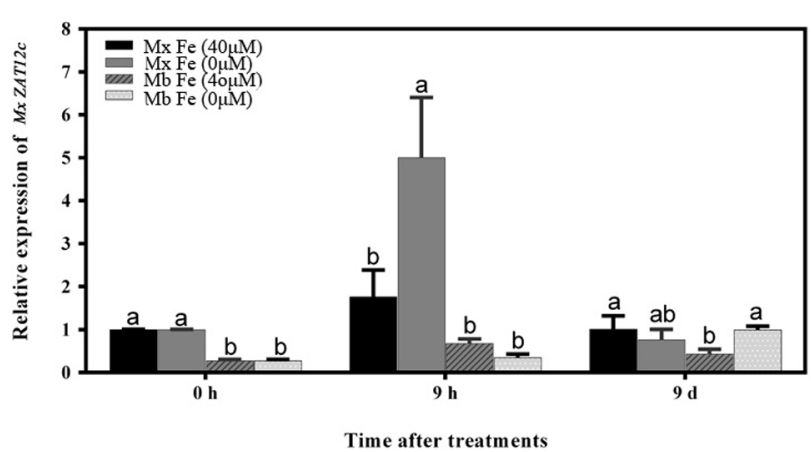

B

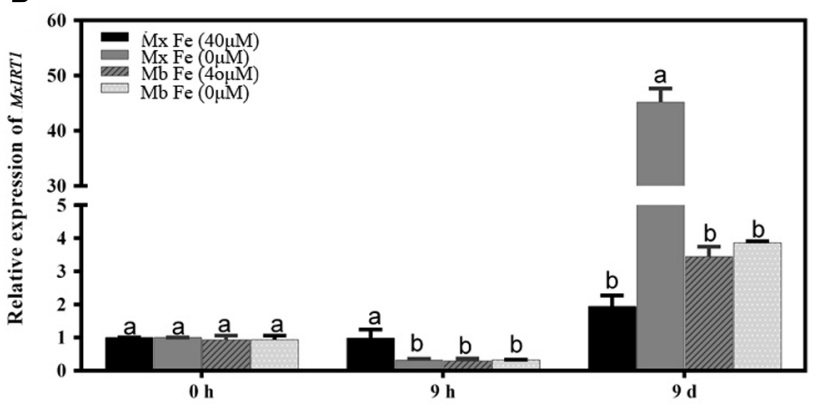

D

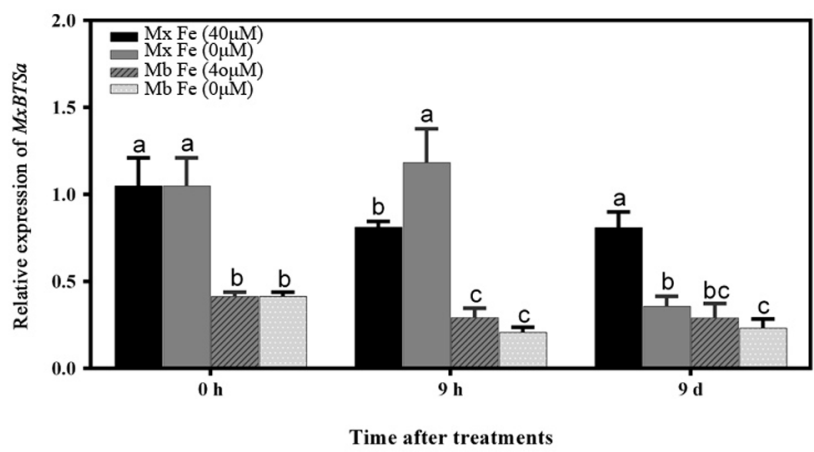

FIGURE 4 | Time course of the expression of different genes under Fe sufficiency and deficiency conditions in $M$. xiaojinensis and $M$. baccata roots. The vertical axis represents the relative gene expression ratios; the horizontal axis represents the times after treatment. The values represent the mean and standard error of three replications. Vertical bars are mean $\pm \mathrm{SE}(n=3)$. Bars carrying different letters are significantly different (Duncan's multiple-range test, $p<0.05)$. (A) The relative expression of MXFIT gene. (B) The relative expression of MxIRT1 gene. (C) The relative expression of MxZat12C gene. (D) The relative expression of MxBTSa gene.

Fe starvation in order to maintain the cellular redox homeostasis. When the high levels of ROS generated exceed the possibility of being controlled by the cell's antioxidant system, oxidative damage is caused (Allen, 1995). GSH and ASC levels have been shown to increase with the progression of Fe deficiency in sugar beet roots (Zaharieva et al., 2004). In A. thaliana, GSH and ASC supplementation preserved cellular redox homeostasis to protect Arabidopsis seedlings from Fe deficiency (Ramírez et al., 2013). Our results suggest that the roots trigger a primary initiation of ROS signaling under Fe deficiency to enhance Fe uptake (Figure 5). However, during prolonged Fe deficiency, the identification of ROS scavengers along with decreased effects of ROS provided a clue as to how this initial ROS production is counterbalanced at the molecular level, possibly to avoid oxidative damage in Fe-efficient woody plants (Figures 4 and 6).

As $\mathrm{Fe}$ is a constituent of enzymes associated with the cellular antioxidant system such as ascorbate peroxidase (APX), CAT, POD, and Fe SOD, plants exposed to Fe deficiency would be more sensitive to oxidative stress (Kumar et al., 2010). In mulberry, maize, and cauliflower it has been suggested that Fe deficiency causes a decrease in CAT, POD, and APX activities (Tewari et al., 2006). Here, it was demonstrated CAT, POD, and SOD levels increased during prolonged $\mathrm{Fe}$ deficiency (Figure 3). We therefore deduced that in the $\mathrm{Fe}$ efficient woody plant $M$. xiaojinensis, but not the Fe-inefficient woody plant $M$. baccata, ROS function mediated the primary Fe deficiency-induced physiological responses. With prolonged Fe deficiency treatment, plants need to cope with elevated ROS production (Figure 7). This underlies the need for a negative regulator of ROS production, such as the scavenging mechanism.

Reactive oxygen species production and associated redox processing are an integral part of hormone regulation and function in the control of plant development and stress tolerance. ROS could also be linked with Fe deficiency regulation since they have been found connected with $\mathrm{NO}$ and ethylene in abiotic stress signaling (Brumbarova et al., 2015; Xia et al., 2015). The stressinduced accumulation of ROS may alter auxin signaling through oxidative inactivation or degradation of auxin, and also be involved in auxin signaling and polar auxin transport (Blomster et al., 2011; Peer et al., 2013; Xia et al., 2015). Previous work in our laboratory showed the Fe deficiency-induced physiological responses are mediated by systemic auxin signaling (Wu et al., 2011). In the present study, we suggested that the ROS could be involved in early stage signaling of the Fe-deficiency responses. Although, the relationship between the auxin and ROS protective responses is not clear, ROS appear to promote stress tolerance by cooperating with auxin. However, as yet, no auxin-ROS that cooperate in response to environmental stresses have been identified. 

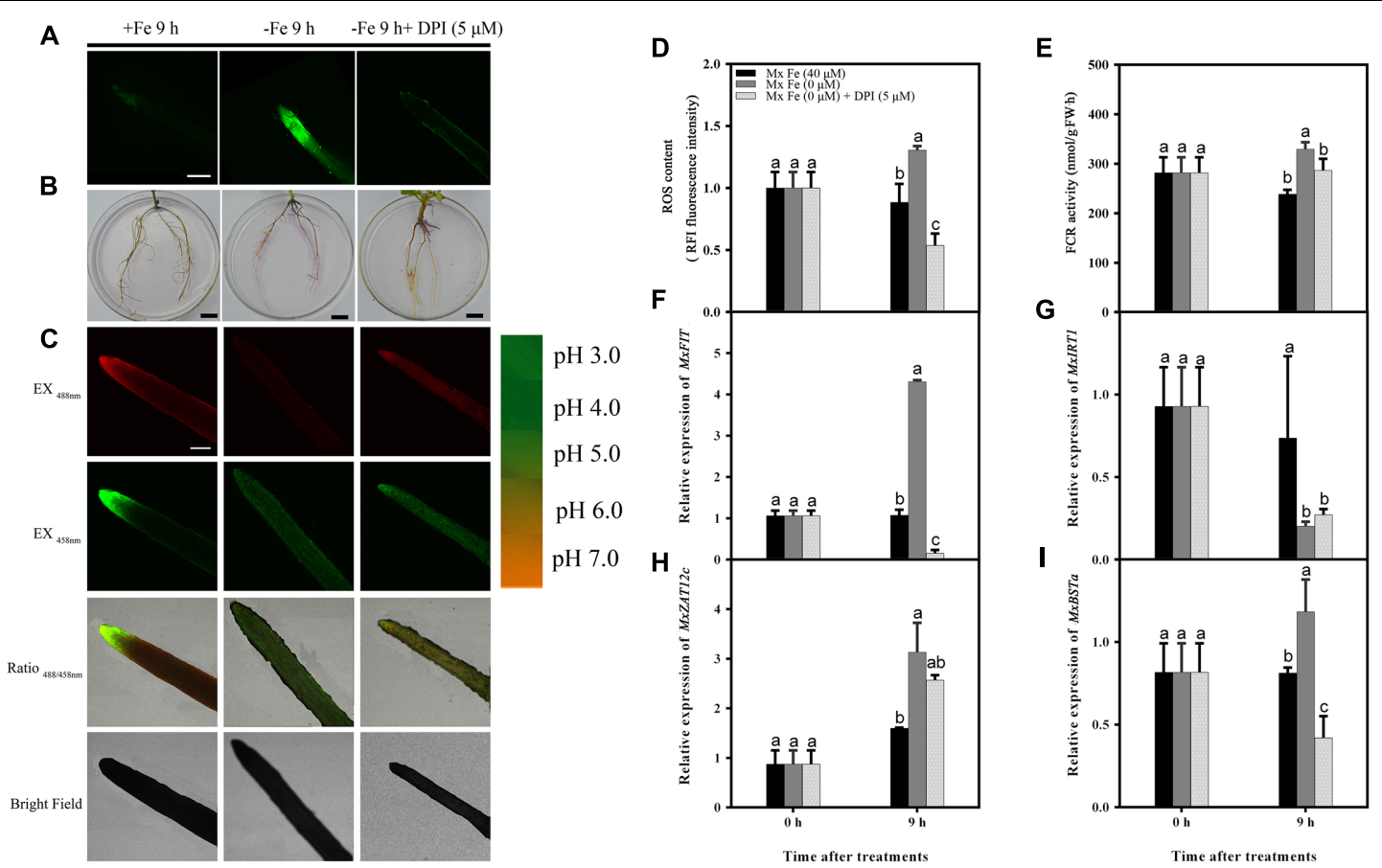

FIGURE 5 | Detection of ROS content, FCR activity, and the expression of different genes in M. xiaojinensis induced by DPI. Seedlings were grown on Fe-sufficient (+Fe) or Fe-deficient (-Fe) medium, or -Fe medium with $5 \mu \mathrm{M}$ DPI for 0 days and 9 h. (A) ROS system localization shown as green fluorescence from DCFH-DA in roots, bar $=500 \mu \mathrm{m}$. (B) Visualization of FCR activity in roots (bars $=1 \mathrm{~cm}$ ). (C) Emission intensities of roots loaded with the pH-sensitive fluorescent dye BCECF at $488 \mathrm{~nm}$ (top, red) and $458 \mathrm{~nm}$ (center, green). The ratio images show a red fluorescence indicating increased root pH in -Fe medium with $5 \mu \mathrm{M}$ DPI compared with -Fe medium. The pseudo-color scale on the right indicates the intensity of fluorescence in which yellow and red represent minimum and maximum intensity, respectively. Bar $=500 \mu \mathrm{m}$. (D) ROS content of root tips (3-5 mm). (E) FCR activity of roots. (F-I) The expression of different genes in M. xiaojinensis roots under early stage iron stress. Vertical bars are mean \pm SE $(n=3)$. Bars carrying different letters are significantly different (Duncan's multiple-range test, $p<0.05)$.

Based on the data presented in this study, a model is proposed for the early stage signaling of the Fe deficiency responses in Fe-efficient woody plants (Figure 7). Our results suggest that the roots first function to perceive the Fe deficiency, which triggers a primary initiation of ROS signaling. The initial ROS production functions to mediate the corresponding responses in the roots only in the Fe-efficient M. xiaojinensis and not the Fe-inefficient $M$. baccata. Further, once the ROS production has been initiated, with prolonged $\mathrm{Fe}$ starvation ROS scavenging mechanisms are activated in $M$. xiaojinensis that are absent in $M$. baccata, which could represent a feedback repression loop for ROS to preserve redox homeostasis and maintain continuous $\mathrm{Fe}$ deficiency responses.

Our study reveals a new mechanism in which ROS mediate both the positive and negative regulation of plant responses to $\mathrm{Fe}$ deficiency stress (Figure 7). Undoubtedly, this work will trigger broad future research to elucidate the mechanisms of how plants adapt to the deficiency of important metal ions.

\section{MATERIALS AND METHODS}

\section{Plant Materials and Growth Conditions}

Malus xiaojinensis seedlings were propagated on Murashige and Skoog medium (MS) (Huayueyang Biotechnology, Co, Ltd,
Beijing, China) containing $0.5 \mathrm{mg} / \mathrm{L}$ 6-benzylaminopurine and $0.3 \mathrm{mg} / \mathrm{L}$ indole-3-butyric acid (IBA) for 1 month, and then transferred to $1 / 2$ MS medium containing $0.5 \mathrm{mg} / \mathrm{L}$ IBA for 1 month for rooting. The rooted seedlings were transferred to Hoagland's nutrient solution (Gao et al., 2011). The $\mathrm{pH}$ was adjusted to $\mathrm{pH} 6.0$ with $1 \mathrm{M} \mathrm{NaOH}$. The solution was refreshed every 6 days. Plants were grown in a growth room at $25 \pm 2^{\circ} \mathrm{C}$ day $/ 17 \pm 2^{\circ} \mathrm{C}$ night with a $16 \mathrm{~h}$ photoperiod at a light intensity of $250 \mathrm{mmol}$ quanta $\mathrm{m}^{2} / \mathrm{s}, 85 \%$ relative humidity. After 1 month, the plants were transferred into Fe-sufficient medium $(40 \mu \mathrm{M} \mathrm{FeNa-}$ EDTA) or Fe-deficient medium ( $0 \mu \mathrm{M}$ FeNa-EDTA) with $50 \mu \mathrm{M}$ DPI or Fe-deficient medium ( $0 \mu \mathrm{M}$ FeNa-EDTA $)$ with $50 \mathrm{mM}$ $\mathrm{H}_{2} \mathrm{O}_{2}$. The roots were collected at 0 days, $9 \mathrm{~h}$, and 9 days during these treatments. A completely randomized experimental design with three biological replicates and three plants for each replicate was used.

\section{Isolation of Total RNA and Synthesis of cDNA}

Total RNA was isolated from the roots using an improved cetyltrimethylammonium bromide (CTAB) method (Gasic et al., 2004). The RNA was digested by DNase I (Takara Biotechnology, Co, Ltd, Dalian, China) and reverse transcribed by using an oligodT primer and reverse transcriptase (Takara Biotechnology, Co, Ltd, Dalian, China). 

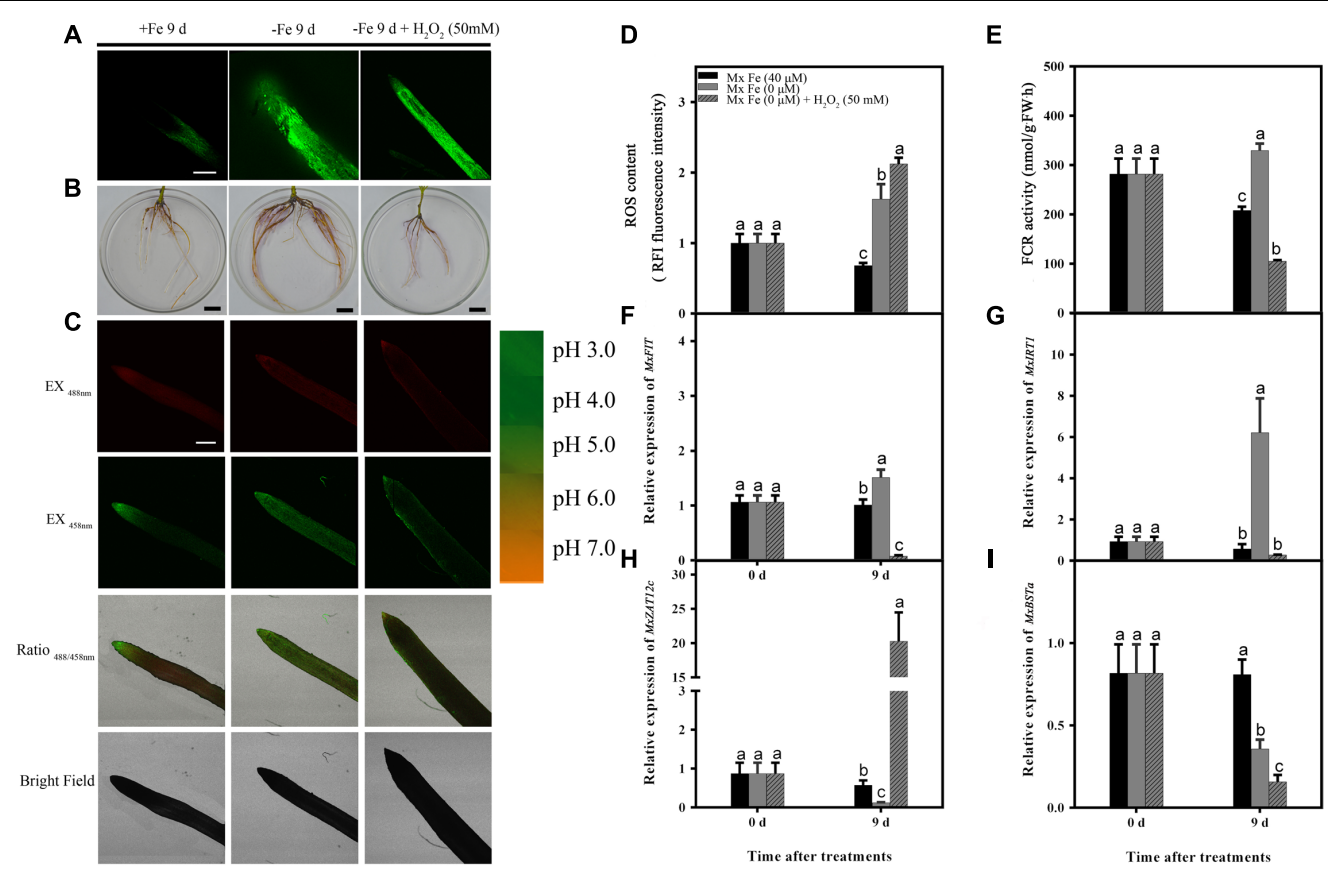

FIGURE 6 | Detection of ROS content, FCR activity, and the expression of different genes in $\mathbf{M}$. xiaojinensis induced by $\mathrm{H}_{2} \mathrm{O}_{2}$. Seedlings were grown on Fe-sufficient (+Fe) or Fe-deficient (-Fe) medium, or -Fe medium with $500 \mathrm{mM} \mathrm{H}_{2} \mathrm{O}_{2}$ for 0 and 9 days. (A) ROS system localization shown as green fluorescence from DCFH-DA in roots, bar $=500 \mu \mathrm{m}$. (B) Visualization of FCR activity in roots (bars $=1 \mathrm{~cm}$ ). (C) Emission intensities of roots loaded with the pH-sensitive fluorescent dye BCECF at $488 \mathrm{~nm}$ (top, red) and $458 \mathrm{~nm}$ (center, green). The ratio images show a red fluorescence indicating increased root pH in -Fe medium with $50 \mathrm{mM} \mathrm{H}_{2} \mathrm{O}$ compared with -Fe medium. The pseudo-color scale on the right indicates the intensity of fluorescence in which yellow and red represent minimum and maximum intensity, respectively. Bar $=500 \mu \mathrm{m}$. (D) ROS content of root tips (3-5 mm). (E) FCR activity of roots. (F-I) The expression of different genes in M. xiaojinensis roots under the later stage of iron stress. Vertical bars are mean \pm SE $(n=3)$. Bars carrying different letters are significantly different (Duncan's multiple-range test, $p<0.05)$.

\section{ROS Localization and Quantification}

Reactive oxygen species were imaged using DCFH-DA and a confocal laser scanning microscope (TE2000-E, Nikon, Co., Tokyo, Japan). Roots (3-5 mm from root tip) were loaded with $20 \mu \mathrm{M}$ DCFH-DA in $20 \mathrm{mM}$ HEPES/ $\mathrm{NaOH} \mathrm{pH} 7.5$ buffer for $90 \mathrm{~min}$, washed three times with fresh buffer, and analyzed microscopically (excitation $488 \mathrm{~nm}$, emission $525 \mathrm{~nm}$ ). The images were analyzed using EZ-C1 3.00 Free View software. For fluorescence quantification per gram of root tissue, roots were loaded with DCFH-DA and washed; the complete root system (approximately $50 \mathrm{mg}$ ) was subsequently ground in $0.5 \mathrm{~mL}$ HEPES/ $\mathrm{NaOH} \mathrm{pH} 7.5$ buffer. The supernatants were then centrifuged $(13,000 \times g, 10 \mathrm{~min})$ at $4^{\circ} \mathrm{C}$, and DCFH-DA concentration was determined by using a fluorescent spectrophotometer (F-7000, Hitachi, Tokyo, Japan) using excitation at $488 \mathrm{~nm}$ and emission at $525 \mathrm{~nm}$. DCFHDA was similarly processed without roots for comparison as a blank. Data are expressed as the mean $\pm \mathrm{SD}$ of two independent experiments performed in triplicate.

\section{Quantification and In situ Localization of $\mathrm{H}_{2} \mathrm{O}_{2}$}

Hydrogen peroxide was detected using the method described by Mukherjee and Choudhuri (1985). A root sample of $200 \mathrm{mg}$ was ground with $1.5 \mathrm{~mL}$ pre-cooled acetone, then centrifuged
$(800 \times g)$ at $4^{\circ} \mathrm{C}$ for $10 \mathrm{~min}$. Then, $5 \%$ titanium sulfate and ammonia water were added to the supernatant, and it was centrifuged again $(800 \times g)$ at $4^{\circ} \mathrm{C}$ for $10 \mathrm{~min}$. The precipitate was rinsed three times with acetone and vortexed. It was then redissolved in $10 \mathrm{M} \mathrm{H}_{2} \mathrm{SO}_{4}$. The absorbance of the supernatant at $415 \mathrm{~nm}$ was measured using an UV spectrophotometer (UV 1800, Shimadzu, Tokyo, Japan); $1.5 \mathrm{~mL}$ acetone was similarly processed without roots for comparison as a blank. The $\mathrm{H}_{2} \mathrm{O}_{2}$ content was determined based on a standard curve plotted using known $\mathrm{H}_{2} \mathrm{O}_{2}$ concentrations. The $\mathrm{H}_{2} \mathrm{O}_{2}$ content was measured as micromoles per gram fresh weight ( $\mu \mathrm{mol} / \mathrm{g} \mathrm{FW})$.

Freshly harvested roots were cut in $5 \mathrm{~mm}$ sections close to the root tip and subjected to protocols for cytochemical localization of $\mathrm{H}_{2} \mathrm{O}_{2} \cdot \mathrm{H}_{2} \mathrm{O}_{2}$ production was assessed cytochemically via determination of cerium perhydroxide formation after reaction of $\mathrm{CeCl}_{3}$ with endogenous $\mathrm{H}_{2} \mathrm{O}_{2}$ (Bestwick et al., 1997). Root sections of $M$. xiaojinensis and $M$. baccata were incubated for $1 \mathrm{~h}$

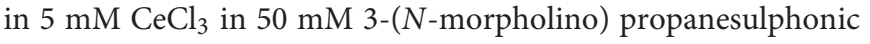
acid (MOPS) $\mathrm{pH} 7.2$, fixed in $1.25 \%$ glutaraldehyde and $1.25 \%$ paraformaldehyde in $50 \mathrm{mM}$ sodium cacodylate buffer (CAB) $\mathrm{pH} 7.2$ by vacuum evacuation of samples for $30 \mathrm{~min}$, and after drying washed three times in $\mathrm{CAB}$ buffer for 10 min (Bestwick et al., 1997). Samples were then embedded in resin and observed by transmission electron microscopy (JEM-1230, JEOL, Tokyo, Japan). 


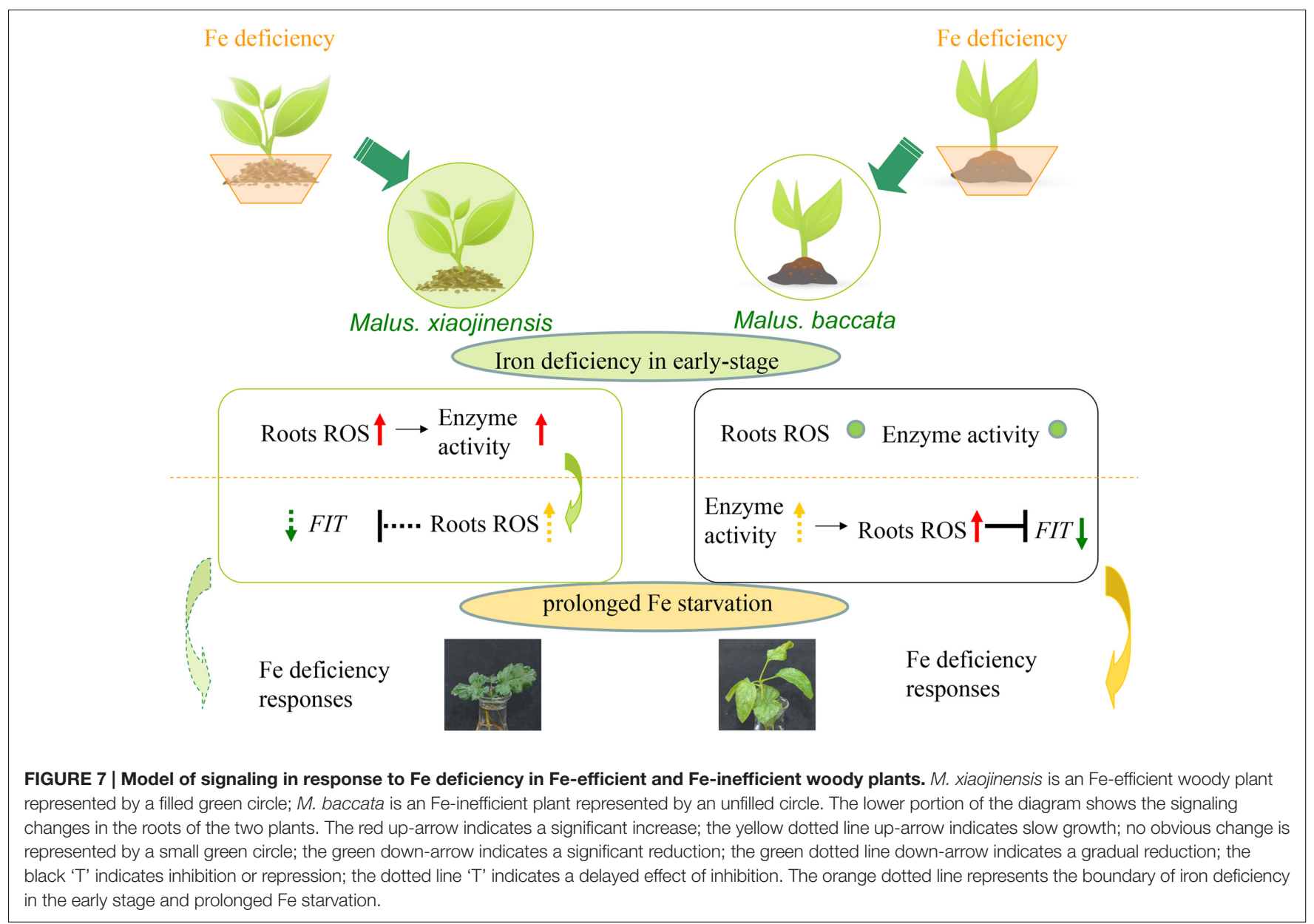

\section{Enzyme Activity Assay}

Root tissue $(0.1 \mathrm{~g})$ was frozen with liquid $\mathrm{N}_{2}$ and homogenized in $2.0 \mathrm{~mL}$ chilled $50 \mathrm{mM}$ phosphate buffer $(\mathrm{pH}$ 7.0). The homogenate was centrifuged at $1,3000 \times \mathrm{g}$, for $20 \mathrm{~min}$ at $4^{\circ} \mathrm{C}$. The supernatant was stored at $4^{\circ} \mathrm{C}$ and used for enzyme assays within $4 \mathrm{~h}$.

Catalase activity was measured in a reaction mixture $(3.0 \mathrm{~mL})$ containing $200 \mu \mathrm{L}$ of the extract, $0.3 \mathrm{~mL} 0.1 \mathrm{mM} \mathrm{H}_{2} \mathrm{O}_{2}$, and $1 \mathrm{~mL}$ distilled water in $0.2 \mathrm{M}$ phosphate $(\mathrm{pH}$ 7.8) containing $1 \%(\mathrm{w} / \mathrm{v})$ insoluble polyvinylpyrrolidone (PVP). The decrease in absorbance at $240 \mathrm{~nm}$ was monitored for $3 \mathrm{~min}$, and the amount of enzyme digesting $1 \mu \mathrm{M}$ substrate in $1 \mathrm{~min}$ was indicated as enzyme activity $(\mu)$ (Tewari et al., 2012). CAT activity was presented as $\mu \mathrm{mol} \mathrm{H}_{2} \mathrm{O}_{2}$ decomposed/min (unit)/mg protein.

Peroxidase activity was estimated in a reaction mixture (3.0 mL) containing $50 \mu \mathrm{L} 50 \mathrm{mM}$ phosphate buffer ( $\mathrm{pH} 7.0)$, $2.9 \mathrm{~mL} 0.3 \%$ guaiacol $(\mathrm{v} / \mathrm{v}), 60 \mu \mathrm{L} 0.004 \% \mathrm{H}_{2} \mathrm{O}_{2}(\mathrm{v} / \mathrm{v})$, and $50 \mu \mathrm{L}$ root extract, and the change in absorbance was measured at $470 \mathrm{~nm}$ (Ranieri et al., 1997). Enzyme activity was expressed as $\Delta \mathrm{Abs} / 0.01 \mathrm{~min}$ (unit)/mg protein.

Superoxide dismutase activity was assayed by measuring its ability to inhibit the photochemical reduction of nitro blue tetrazolium (NBT) at $560 \mathrm{~nm}$. The reaction mixture $(3.0 \mathrm{~mL})$ contained $1.5 \mathrm{~mL} 50 \mathrm{mM}$ phosphate buffer ( $\mathrm{pH} 7.8), 300 \mu \mathrm{L}$
$750 \mu \mathrm{M}$ NBT, $300 \mu \mathrm{L} 20 \mu \mathrm{M}$ riboflavin, $50 \mu \mathrm{L}$ root enzyme extract, $300 \mu \mathrm{L} 130 \mathrm{mM}$ methionine (Met), and $1 \mathrm{~mL}$ distilled water (Bradford, 1976). The reaction mixture was exposed to light at $4000 \mathrm{Lx}$ for $10 \mathrm{~min}$. The amount of SOD corresponding to 50\% inhibition of the reaction was defined as one unit of enzyme. SOD activity was expressed as $\mathrm{U}$ (unit)/mg protein.

\section{FCR Activity Determination and Visualization}

The root FCR activity was quantified using a ferrozine assay (Schikora and Schmidt, 2001). All reduction assays were performed in $15 \mathrm{~mL}$ lightproof centrifuge tubes. The roots were initially washed in $0.5 \mathrm{mM} \mathrm{CaSO}_{4}$ for $5 \mathrm{~min}$, and then the color reaction was carried out in a solution of $0.5 \mathrm{mM}$ ferrozine, $0.5 \mathrm{mM} \mathrm{FeNa-EDTA}$, and $0.5 \mathrm{mM} \mathrm{CaSO}_{4}$ at $25^{\circ} \mathrm{C}$ for $40 \mathrm{~min}$. The reaction was adjusted to $\mathrm{pH} 6.0$ with $1 \mathrm{M}$ $\mathrm{NaOH}$. Reduction activity was measured at $562 \mathrm{~nm}$ using a spectrophotometer (UV 1800, Shimadzu, Japan). The reduction rate was calculated after subtraction of the appropriate blanks (assay solution without roots). The rate of root FCR activity was calculated as moles of $\mathrm{Fe}^{2+}$-ferrozine per gram of fresh weight per hour. Data, expressed as the mean $\pm \mathrm{SD}$, represent three biological replicates, with each replicate containing four plant root samples. To visualize FCR activity spatially, the plant roots 
were initially pre-processed and then embedded in agarose $(0.7 \%$, $\mathrm{w} / \mathrm{v})$ medium containing the assay solution. Photographs were taken after $40 \mathrm{~min}$ (Li et al., 2000).

\section{Measurement of Root pH}

Root $\mathrm{pH}$ of apple $M$. xiaojinensis was monitored with the cellpermeant and $\mathrm{pH}$-sensitive fluorescent dye BCECF-AM (Tang et al., 2012). Root pH was quantified by a ratio analysis of the fluorescence at $\mathrm{pH}$-dependent $(488 \mathrm{~nm})$ and $\mathrm{pH}$-independent (458 nm) excitation wavelengths from a calibration curve (Supplementary Figure S2), and ratio images were produced using the ion concentration tool of Zeiss LSM confocal software.

\section{Measurement of Extra Iron Content}

Approximately, $1 \mathrm{~g}$ of roots was maintained at $70^{\circ} \mathrm{C}$ for 7 days. One hundred milligrams of each dried sample was then treated with $10 \mathrm{ml} 1.0 \mathrm{M} \mathrm{HCl}$ in an orbital shaker for $6 \mathrm{~h}$, and the filtered extract was analyzed by polarized Zeeman atomic absorption spectrophotometry (Z-5000; Hitachi, Tokyo, Japan) (Takkar and Kaur, 1984; Han et al., 1994).

\section{Chemicals}

DCFH-DA (Dichlorofluorescein diacetate) and BCECF-AM (3'-O-Acetyl-2',7'-bis(carboxyethyl)-4) were purchased from Beyotime Institute of Biotechnology, Product codes S0033 and S1006 ${ }^{1}$; DPI, HEPES, and ferrozine were from Sigma ${ }^{2}$.

\section{Freeze-Drying Microtomy and SR-mXRF}

Root samples of $1 \mathrm{~cm}$ length were cut off from the root tip and embedded quickly. The embedded root samples were sliced into $200 \mathrm{~mm}$ thick longitudinal and latitudinal sections with a freezing microtome (LEICA-CM 3050 S, Germany) and placed on Kapton tape, then freeze-dried (LGJ-10B, Beijing Four-Ring Science Instrument Factory) for about $24 \mathrm{~h}$ for SR-mXRF analysis.

The SR-mXRF microspectroscopy experiment was performed at $4 \mathrm{~W} 1 \mathrm{~B}$ end station, Beijing synchrotron Radiation Facility, which runs a $2.5 \mathrm{GeV}$ electron beam with a current from 150 to $250 \mathrm{~mA}$. The incident X-ray energy was monochromatized by a W/B4C Double-Multilayer Monochromator at $15 \mathrm{keV}$ and was focused down to $50 \mu \mathrm{m}$ in diameter by the polycapillary lens. The two-dimensional mapping was acquired by step mode: the sample was kept on a precision motor-driven stage, scanning $50 \mu \mathrm{m}$ stepwise for latitudinal samples and $100 \mu \mathrm{m}$ stepwise for longitudinal samples. The $\mathrm{Si}(\mathrm{Li})$ solid-state detector was used to detect X-ray fluorescence emission lines with live time of $60 \mathrm{~s}$. The data reduction and process were performed using the PyMCA ${ }^{3}$ package (Solé et al., 2007).

\section{Analysis of Gene Expression}

The quantitative measurement of gene expression was performed using the cDNA samples with an AB7500 Real-time PCR System and the SYBR Green fluorescence dye (Takara) (Li et al., 2012).

\footnotetext{
${ }^{1}$ http://www.beyotime.com/goods.do?method=getmain

${ }^{2}$ http://www.sigmaaldrich.com/

${ }^{3}$ http://sourceforge.net/projects/pymca/
}

The genes analyzed were the following: Fe deficiency-induced transcription factor MxFIT1 (NCBI: XP_008360009.1), $\mathrm{Fe}^{2+}$ transporter MxIRT1 (NCBI: AAO17059.1), Malus $\times$ domestica zinc finger protein MxZAT12c (NCBI: XM_008371622), putative E3 ligase BRUTUS MxBTSa (NCBI: XP_008393323.1). The sequences of all of the genes in the apple genome were obtained from the website http://genomics.research.iasma.it/ via its BLAST (basic local alignment search tool) service. Based on the BLASTP results in $\mathrm{NCBI}^{4}$ for those proteins encoded by the genes examined, primers were designed using Primer Premier 5 (Primer, Co., Canada). The $\beta$-Actin was used as the reference gene. The primer sets used are listed in Supplementary Table S1.

\section{Statistical Analysis}

Statistical analysis was performed using the Statistical Product and Service Solutions (SPSS) software (IBM, Co., Armonk, NY, USA). All experimental data were tested by analysis of variance (ANOVA) and Duncan's multiple-range test.

\section{AUTHOR CONTRIBUTIONS}

YW and ZH conceived and designed research. CS, TW, and LZ conducted experiments. DL, XZ, XX, and HM contributed new reagents and analytical tools. CS and TW wrote the manuscript. All authors read and approved the manuscript.

\section{FUNDING}

Financial support was provided by the National Natural Science Foundation of China (No. 31272139), Special Fund for Agroscientific Research in the Public Interest (201203075 and 201303093), the earmarked fund for China Agriculture Research System (CARS-28), the Special Scientific Research Fund of agriculture Public Welfare Profession of China (Grant No. 201303093), and Key Lab of Nutrition and Physiology for Horticultural Crops.

\section{ACKNOWLEDGMENTS}

The $\mu$-XRF beam time was granted by $4 \mathrm{~W} 1 \mathrm{~B}$ beamline of Beijing Synchrotron Radiation Facility, Institute of High Energy Physics - Chinese Academy of Sciences. The staff members of $4 \mathrm{~W} 1 \mathrm{~B}$ are acknowledged for their support in measurements and data reduction.

\section{SUPPLEMENTARY MATERIAL}

The Supplementary Material for this article can be found online at: http://journal.frontiersin.org/article/10.3389/fpls.2016.01726/ full\#supplementary-material

FIGURE S1 | Reactive oxygen species and $\mathrm{H}_{2} \mathrm{O}_{2}$ content of $M$. xiaojinensis $(\mathrm{Mx})$ and $M$. baccata (Mb) plants with Fe-sufficient (+Fe) and Fe-deficient

${ }^{4}$ http://www.ncbi.nlm.nih.gov/ 
(-Fe) treatment. (A) ROS content in root tips (3-5 mm). (B) $\mathrm{H}_{2} \mathrm{O}_{2}$ content in roots.

FIGURE S2 | In situ calibration of BCECF-AM in $M$. xiaojinensis root tips. (A) M. xiaojinensis root tips loaded with BCECF were imaged at $488 \mathrm{~nm}$ (top row,

\section{REFERENCES}

Allen, R. D. (1995). Dissection of oxidative stress tolerance using transgenic plants. Plant Physiol. 107, 1049. doi: 10.1104/pp.107.4.1049

Bauer, P., Ling, H. Q., and Guerinot, M. L. (2007). FIT, the FER-like iron deficiency induced transcription factor in Arabidopsis. Plant Physiol. Biochem. 45, 260261. doi: 10.1016/j.plaphy.2007.03.006

Baxter, A., Mittler, R., and Suzuki, N. (2014). ROS as key players in plant stress signalling. J. Exp. Bot. 65, 1229-1240. doi: 10.1093/jxb/ert375

Bestwick, C. S., Brown, I. R., Bennett, M., and Mansfield, J. W. (1997). Localization of hydrogen peroxide accumulation during the hypersensitive reaction of lettuce cells to Pseudomonas syringae pv phaseolicola. Plant Cell 9, 209-221. doi: 10.1105/tpc.9.2.209

Blomster, T., Salojärvi, J., Sipari, N., Brosché, M., Ahlfors, R., Keinänen, M., et al. (2011). Apoplastic reactive oxygen species transiently decrease auxin signaling and cause stress-induced morphogenic response in Arabidopsis. Plant Physiol. 157, 1866-1883. doi: 10.1104/pp.111.181883

Bradford, M. M. (1976). A rapid and sensitive method for the quantitation of microgram quantities of protein utilizing the principle of protein-dye binding. Anal. Biochem. 72, 248-254. doi: 10.1016/0003-2697(76)90527-3

Briat, J. F., Duc, C., Ravet, K., and Gaymard, F. (2010). Ferritins and iron storage in plants. Biochim. Biophys. Acta 1800, 806-814. doi: 10.1016/j.bbagen.2009.12.003

Briat, J. F., Fobis-Loisy, I., Grignon, N., Lobréaux, S., Pascal, N., Savino, G., et al. (1995). Cellular and molecular aspects of iron metabolism in plants. Biol. Cell 84, 69-81. doi: 10.1016/0248-4900(96)81320-7

Brumbarova, T., Bauer, P., and Ivanov, R. (2015). Molecular mechanisms governing Arabidopsis iron uptake. Trends Plant Sci. 20, 124-133. doi: 10.1016/j.tplants.2014.11.004

Chen, V. B., Arendall, W. B., Headd, J. J., Keedy, D. A., Immormino, R. M., Kapral, G. J., et al. (2010). MolProbity: all-atom structure validation for macromolecular crystallography. Acta Crystallogr. D Biol. Crystallogr. 66, $12-$ 21. doi: $10.1107 /$ S0907444909042073

Crichton, R., and Pierre, J. L. (2001). Old iron, young copper: from Mars to Venus. Biometals 14, 99-112. doi: 10.1023/A:1016710810701

da Silva, E. C., Nogueira, R. J. M. C., de Araújo, F. P., de Melo, N. F., and de Azevedo Neto, A. D. (2008). Physiological responses to salt stress in young umbu plants. Environ. Exp. Bot. 63, 147-157. doi: 10.1016/j.envexpbot.2007. 11.010

Darbani, B., Briat, J. F., Holm, P. B., Husted, S., Noeparvar, S., and Borg, S. (2013). Dissecting plant iron homeostasis under short and long-term iron fluctuations. Biotechnol. Adv. 31, 1292-1307. doi: 10.1016/j.biotechadv.2013.05.003

Dietz, K. J. (2008). Redox signal integration: from stimulus to networks and genes. Physiol. Plant. 133, 459-468. doi: 10.1111/j.1399-3054.2008.01120.x

Gao, C., Wang, Y., Xiao, D. S., Qiu, C. P., Han, D. G., Zhang, X. Z., et al. (2011). Comparison of cadmium-induced iron-deficiency responses and genuine irondeficiency responses in Malus xiaojinensis. Plant Sci. 181, 269-274. doi: 10.1016/j.plantsci.2011.05.014

Gasic, K., Hernandez, A., and Korban, S. S. (2004). RNA extraction from different apple tissues rich in polyphenols and polysaccharides for cDNA library construction. Plant Mol. Biol. Rep. 22, 437-438. doi: 10.1007/BF02772687

Han, Z. H., Han, C. Q., Xu, X. F., and Wang, Q. (2005). Relationship between iron deficiency stress and endogenous hormones in iron-efficient versus inefficient apple genotypes. J. Plant Nutr. 28, 1887-1895. doi: 10.1080/01904160500306391

Han, Z. H., Shen, T., Korcak, R., and Baligar, V. (1998). Iron absorption by iron-efficient and-inefficient species of apples. J. Plant Nutr. 21, 181-190. doi: $10.1080 / 01904169809365392$

Han, Z. H., Wang, Q., and Shen, T. (1994). Comparison of some physiological and biochemical characteristics between iron-efficient and iron-inefficient species in the genus malus. J. Plant Nutr. 17, 1257-1264. doi: 10.1080/01904169409364803 red) and $458 \mathrm{~nm}$ (second row, green) excitation of BCECF. Ratio images were pseudo-colored to show the $\mathrm{pH}$ gradient (third row). Bright-field images were also captured from the same root samples (bottom row). Bar $=500 \mu \mathrm{m}$. (B) The fluorescence ratios ( $488 / 458 \mathrm{~nm}$ ) were plotted against the $\mathrm{pH}$ of the equilibration buffers to generate a calibration curve.

Huang, X., and Han, B. (2014). Natural variations and genome-wide association studies in crop plants. Annu. Rev. Plant Biol. 65, 531-551. doi: 10.1146/annurevarplant-050213-035715

Krasensky, J., and Jonak, C. (2012). Drought, salt, and temperature stress-induced metabolic rearrangements and regulatory networks. J. Exp. Bot. 63, 1593-1608. doi: 10.1093/jxb/err460

Kumar, A., Prakash, A., and Dogra, S. (2010). Naringin alleviates cognitive impairment, mitochondrial dysfunction and oxidative stress induced by D-galactose in mice. Food Chem. Toxicol. 48, 626-632. doi: 10.1016/j.fct.2009.11.043

Le, C. T. T., Brumbarova, T., Ivanov, R., Stoof, C., Weber, E., Mohrbacher, J., et al. (2016). ZINC FINGER OF ARABIDOPSIS THALIANA12 (ZAT12) interacts with FER-LIKE IRON DEFICIENCY-INDUCED TRANSCRIPTION FACTOR (FIT) linking iron deficiency and oxidative stress responses. Plant Physiol. 170, 540-557. doi: 10.1104/pp.15.01589

Li, C. J., Zhu, X. P., and Zhang, F. S. (2000). Role of shoot in regulation of iron deficiency responses in cucumber and bean plants. J. Plant Nutr. 23, 1809-1818. doi: 10.1080/01904160009382144

Li, T. Y., Wang, Y., Zhang, X. Z., and Han, Z. H. (2012). Isolation and characterization of ARRO-1 genes from apple rootstocks in response to auxin treatment. Plant Mol. Biol. Rep. 30, 1408-1414. doi: 10.1007/s11105-012-0457-z

Long, T. A., Tsukagoshi, H., Busch, W., Lahner, B., Salt, D. E., and Benfey, P. N. (2010). The bHLH transcription factor POPEYE regulates response to iron deficiency in Arabidopsis roots. Plant Cell 22, 2219-2236. doi: $10.1105 /$ tpc. 110.074096

Marschner, H. (2011). Marschner's Mineral Nutrition of Higher Plants, 3rd Edn. London: Academic Press.

Marschner, H., Römheld, V., and Kissel, M. (1986). Different strategies in higher plants in mobilization and uptake of iron. J. Plant Nutr. 9, 695-713. doi: 10.1080/01904168609363475

Miller, M. A., Pfeiffer, W., and Schwartz, T. (2010). "Creating the CIPRES science gateway for inference of large phylogenetic trees," in Proceedings of the Gateway Computing Environments Workshop (GCE), New Orleans, LA, 1-8.

Mittler, R., Vanderauwera, S., Gollery, M., and Van Breusegem, F. (2004). Reactive oxygen gene network of plants. Trends Plant Sci. 9, 490-498. doi: 10.1016/j.tplants.2004.08.009

Mukherjee, S., and Choudhuri, M. (1985). Implication of hydrogen peroxideascorbate system on membrane permeability of water stressed vignaseedlings. New Phytol. 99, 355-360. doi: 10.1111/j.1469-8137.1985.tb03663.x

Noctor, G., Mhamdi, A., and Foyer, C. H. (2014). The roles of reactive oxygen metabolism in drought: not so cut and dried. Plant Physiol. 164, 1636-1648. doi: $10.1104 /$ pp.113.233478

Peer, W. A., Cheng, Y., and Murphy, A. S. (2013). Evidence of oxidative attenuation of auxin signalling. J. Exp. Bot. 64, 2629-2639. doi: 10.1093/jxb/ert152

Ramírez, L., Bartoli, C. G., and Lamattina, L. (2013). Glutathione and ascorbic acid protect Arabidopsis plants against detrimental effects of iron deficiency. J. Exp. Bot. 64, 3169-3178. doi: 10.1093/jxb/ert153

Ranieri, A., Castagna, A., Baldan, B., and Soldatini, G. F. (2001). Iron deficiency differently affects peroxidase isoforms in sunflower. J. Exp. Bot. 52, 25-35. doi: 10.1093/jexbot/52.354.25

Ranieri, A., Castagna, A., Lorenzini, G., and Soldatini, G. (1997). Changes in thylakoid protein patterns and antioxidant levels in two wheat cultivars with different sensitivity to sulfur dioxide. Environ. Exp. Bot. 37, 125-135. doi: 10.1016/S0098-8472(96)01040-4

Ravet, K., Reyt, G., Arnaud, N., Krouk, G., Djouani, E. B., Boucherez, J., et al. (2012). Iron and ROS control of the DownSTream mRNA decay pathway is essential for plant fitness. EMBO. J. 31, 175-186. doi: 10.1038/emboj.2011.341

Ravet, K., Touraine, B., Boucherez, J., Briat, J. F., Gaymard, F., and Cellier, F. (2009). Ferritins control interaction between iron homeostasis and oxidative stress in Arabidopsis. Plant J. 57, 400-412. doi: 10.1111/j.1365-313X.2008.03698.x 
Reyt, G., Boudouf, S., Boucherez, J., Gaymard, F., and Briat, J. F. (2015). Iron-and ferritin-dependent reactive oxygen species distribution: impact on Arabidopsis root system architecture. Mol. Plant 8, 439-453. doi: 10.1016/j.molp.2014.11.014

Romera, F. J., and Alcántara, E. (2004). Ethylene involvement in the regulation of Fe-deficiency stress responses by Strategy I plants. Funct. Plant Biol. 31, 315-328. doi: 10.1071/FP03165

Römheld, V., and Marschner, H. (1990). Genotypical differences among graminaceous species in release of phytosiderophores and uptake of iron phytosiderophores. Plant Soil 123, 147-153. doi: 10.1007/BF000 11260

Schikora, A., and Schmidt, W. (2001). Iron stress-induced changes in root epidermal cell fate are regulated independently from physiological responses to low iron availability. Plant Physiol. 125, 1679-1687. doi: 10.1104/pp.125.4.1679

Schmidt, W., and Bartels, M. (1996). Formation of root epidermal transfer cells in Plantago. Plant Physiol. 110, 217-225. doi: 10.1104/pp.110.1.217

Solé, V., Papillon, E., Cotte, M., Walter, P., and Susini, J. (2007). A multiplatform code for the analysis of energy-dispersive X-ray fluorescence spectra. Spectrochim. Acta B At. Spectrosc. 62, 63-68. doi: 10.1016/j.sab.2006. 12.002

Sudre, G., Inceoglu, S., Cotanda, P., and Balsara, N. P. (2013). Influence of bound ion on the morphology and conductivity of anion-conducting block copolymers. Macromolecules 46, 1519-1527. doi: 10.1021/ma302357k

Sun, B., Jing, Y., Chen, K., Song, L., Chen, F., and Zhang, L. (2007). Protective effect of nitric oxide on iron deficiency-induced oxidative stress in maize (Zea mays). J. Plant physiol. 164, 536-543. doi: 10.1016/j.jplph.2006.02.011

Sun, L., Xia, L., Yi, S., Lenaghan, S. C., Wang, Y., and Zhang, M. (2013). Biosynthesis of metal nanoparticles from the peel of asparagus lettuce (Lactuca sativa var. asparagine). Adv. Sci. 5, 1157-1165.

Suzuki, N., Koussevitzky, S., Mittler, R., and Miller, G. (2012). ROS and redox signalling in the response of plants to abiotic stress. Plant Cell Environ. 35, 259-270. doi: 10.1111/j.1365-3040.2011.02336.x

Takkar, P., and Kaur, N. (1984). HCl method for Fe2+ estimation to resolve iron chlorosis in plants. J. Plant Nutr. 7, 81-90. doi: 10.1080/01904168409363176

Tang, R. J., Liu, H., Yang, Y., Yang, L., Gao, X. S., Garcia, V. J., et al. (2012). Tonoplast calcium sensors CBL2 and CBL3 control plant growth and ion homeostasis through regulating V-ATPase activity in Arabidopsis. Cell Res. 22, 1650-1665. doi: 10.1038/cr.2012.161

Tewari, R. K., Kumar, P., and Sharma, P. N. (2006). Magnesium deficiency induced oxidative stress and antioxidant responses in mulberry plants. Sci. Hortic. 108, 7-14. doi: 10.1016/j.scienta.2005.12.006

Tewari, R. K., Watanabe, D., and Watanabe, M. (2012). Chloroplastic NADPH oxidase-like activity-mediated perpetual hydrogen peroxide generation in the chloroplast induces apoptotic-like death of Brassica napus leaf protoplasts. Planta 235, 99-110. doi: 10.1007/s00425-011-1495-8

Wang, C., and Li, D. (1995). Solvent extraction of Sc (III), Zr (lV), Th (IV), Fe (lll), and $\mathrm{Lu}$ (lll) with thiosubstituted organophosphinic acid extractants. Solv. Extr. Ion Exch. 13, 503-523. doi: 10.1080/07366299508 918288

Wu, G., Mack, N. H., Gao, W., Ma, S., Zhong, R., Han, J., et al. (2012). Nitrogen-doped graphene-rich catalysts derived from heteroatom polymers for oxygen reduction in nonaqueous lithium-O2 battery cathodes. ACS Nano 6, 9764-9776. doi: 10.1021/nn303275d

Wu, J., Wang, C., Zheng, L., Wang, L., Chen, Y., Whelan, J., et al. (2011). Ethylene is involved in the regulation of iron homeostasis by regulating the expression of iron-acquisition-related genes in Oryza sativa. J. Exp. Bot. 62, 667-674. doi: 10.1093/jxb/erq301

Xia, X. J., Gao, C. J., Song, L. X., Zhou, Y. H., Shi, K., and Yu, J. Q. (2014). Role of $\mathrm{H} 2 \mathrm{O} 2$ dynamics in brassinosteroid-induced stomatal closure and opening in Solanum lycopersicum. Plant Cell Environ. 37, 2036-2050. doi: $10.1111 /$ pce. 12275

Xia, X. J., Zhou, Y. H., Shi, K., Zhou, J., Foyer, C. H., and Yu, J. Q. (2015). Interplay between reactive oxygen species and hormones in the control of plant development and stress tolerance. J. Exp. Bot. 66, 2839-2856. doi: 10.1093/jxb/erv089

Xu, L., Wang, Y. F., Cheng, X., Kang, Y. J., and Wang, M. L. (2009). Effects of phosphorus application on root growth and development and yield of Peanut (Arachis hypogaea L.). J. Peanut Sci. 1:2.

Yuan, Y. X., Zhang, J., Wang, D. W., and Ling, H. Q. (2005). AtbHLH29 of Arabidopsis thaliana is a functional ortholog of tomato FER involved in controlling iron acquisition in strategy I plants. Cell Res. 15, 613-621. doi: 10.1038/sj.cr.7290331

Zaharieva, T., Gogorcena, Y., and Abadìa, J. (2004). Dynamics of metabolic responses to iron deficiency in sugar beet roots. Plant Sci. 166, 1045-1050. doi: 10.1016/j.plantsci.2003.12.017

Zaharieva, T., Yamashita, K., and Matsumoto, H. (1999). Iron deficiency induced changes in ascorbate content and enzyme activities related to ascorbate metabolism in cucumber roots. Plant Cell Physiol. 40, 273-280. doi: 10.1093/oxfordjournals.pcp.a029538

Zaharieva, T. B., and Abadia, J. (2003). Iron deficiency enhances the levels of ascorbate, glutathione, and related enzymes in sugar beet roots. Protoplasma $221,269-275$

Conflict of Interest Statement: The authors declare that the research was conducted in the absence of any commercial or financial relationships that could be construed as a potential conflict of interest.

Copyright (c) 2016 Sun, Wu, Zhai, Li, Zhang, Xu, Ma, Wang and Han. This is an open-access article distributed under the terms of the Creative Commons Attribution License (CC BY). The use, distribution or reproduction in other forums is permitted, provided the original author(s) or licensor are credited and that the original publication in this journal is cited, in accordance with accepted academic practice. No use, distribution or reproduction is permitted which does not comply with these terms. 